\title{
Preparation of a Comprehensive Earthquake Catalog for Northeast India and its completeness analysis
}

\author{
Pulama Talukdar* \\ Department of Physics, .Barbhag College, Kalag, Nalbari, Assam, India
}

\begin{abstract}
Being seismically most active, Northeast India claims the need of high quality of seismic investigation to mitigate the risk of lives and properties of the region for which a well documented earthquake catalog is of prime importance. But the seismic surveillance of the area was in infantile stage till the 7th decade of last century. Prior to which scientific information about earthquakes of the area was not available. In the present study an attempt has been made to prepare a comprehensive earthquake catalog pertaining the rectangular area from $21^{0} \mathrm{~N}$ to $29.5^{\circ} \mathrm{N}$ and $88^{0} \mathrm{E}$ to $97.5^{\circ} \mathrm{E}$ for last 110 years based on the available catalog of United States Geological Survey and International seismological Center. The catalog is analyzed for completeness magnitude $\left(M_{c}\right)$ using Gutenberg's Frequency Magnitude Distribution (FMD) law and it is found to be $4 M_{b}$. The completeness time of reported magnitude is assessed by Stepp Method, (1972). The completeness analysis shows that the catalog is complete for whole period for larger magnitude $\geq 7 M_{b}$. Earthquakes having magnitude range 6-6.9 $M_{b}, 5-5.9 M_{b}$ and 4- $4.9 M_{b}$ may be considered to be completely recorded since 1921, 1961 and 1991 respectively.
\end{abstract}

Keywords: Earthquake Catalog, completeness magnitude, Frequency magnitude distribution, completeness analysis.

\section{Introduction:}

An accurate, complete and comprehensive earthquake catalog is necessary for the study of earthquake behavior, testing hypothesis, earthquake resistant designing and understanding geodynamic process associated with earthquakes. But most of the catalogs are heterogeneous and inconsistent in space and time and usually incomplete for small events due to the limited sensitivity and coverage of the earth by seismographic networks. In India reliable information on instrumental magnitudes and locations are available after $1964^{1,2}$. Shillong was the only seismic station till very recently in Northeast India and at present the area is covered by more than 20 digital seismic centers ${ }^{3}$. Catalog accuracy includes the completeness of the earthquake list as well as an estimate of errors or uncertainties in determining earthquake parameters. The uncertainties in terms of origin time, location, depth and magnitude can be tested by comparing local with worldwide earthquake catalog ${ }^{4-10}$ while the completeness of a data series is generally tested by examining it in reference to the Gutenberg - Richter law ${ }^{11,12}$. The assessment of the magnitude of completeness, $M_{c}$, is one of the specific aspects of quality control of a data set. $\mathrm{M}_{\mathrm{c}}$ is developed as the lowest magnitude at which $100 \%$ of the events in a space time volume are detected ${ }^{13-15}$. Scientific information about earthquakes of the northeast India is available towards the close of twentieth century and well documented earthquake catalog for this region is found only for a few decades. A comprehensive data file for the period 01/01/1901 to 20/03/2011 has been prepared for the study region on the basis of the available catalog and analyzed for completeness and lengths of unbiased datasets for different magnitude have been estimated.

\section{Data Source And Methodology:}

The present catalog is based on compilation of ISC (International Seismological Center) and USGS (United States Geological Survey) catalogs. This combined catalog for the study pertains to the rectangular area from $21^{0} \mathrm{~N}$ to $29.5^{\circ} \mathrm{N}$ latitude and $88^{0} \mathrm{E}$ to $97.5^{\circ} \mathrm{E}$ longitude. To prepare a comprehensive data base the sources are compared with each year record. The record of the particular year with the maximum number of earthquakes is selected to construct the database of the specific year. This is done for each year till the database is completed and duplication is carefully avoided by comparing the time and location of the events. Surface wave magnitude $M_{s}$ and body wave magnitude $M_{b}$ both is adopted. To convert the data from one from the other Richter relation ${ }^{16} \mathrm{M}_{\mathrm{b}}=2.5+.63 \mathrm{M}_{\mathrm{s}}$ is used. The total number of earthquakes in the combined catalog is 2631 . The minimum magnitude is $3.5 \mathrm{M}_{\mathrm{b}}$. The catalog was intended to prepare from 1900 , but the $1^{\text {st }}$ recorded data was found on $31^{\text {st }}$ August of 1906 . So, the starting date for the catalog is 31/08/1906 and it is continued till the last event on 20/03/2011. 


\section{Completeness Analysis:}

The incompleteness of an earthquake dataset that comes in because of the non-uniformity of the seismic networks with time is investigated generally by fitting a Gutenberg-Richter model to the frequency magnitude distribution (FMD). The FMD ${ }^{17}, 18$ described the relationship between the frequency of occurrence and magnitude of earthquakes as-

$\log N(M)=a-b(M)$

Where $N(M)$ is the number of earthquake of magnitude $\geq M$, ' $a$ ' is the number of earthquakes of magnitude larger than 0 and ' $b$ ' describes the relative distribution of small and large earthquake. The value of ' $a$ ' and ' $b$ ' are generally determined by fitting the observed data sample. The relation has been confirmed for the global seismicity as well as for regional seismicity in different seismic zones of the world ${ }^{19}$ for a homogeneous data series equation (1) fits well and it gives considerably stable recurrence rate of earthquakes. But in practice as mentioned earlier the available catalogs of earthquakes are not complete especially for smaller magnitude events i.e. catalog are biased against small events. The magnitude at which the lower end of FMD departs from the linear trend in the log-linear plot $^{20}$ is taken as the magnitude of completeness $\left(\mathrm{M}_{\mathrm{c}}\right)$. It should be emphasized that only deviation from linearity at small magnitude (lower end of the FMD) is considered; deviation at larger magnitude (upper end of the FMD) can be due to statistical fluctuations due to under sampling or to a real break in G-R scaling ${ }^{21,22}$. Completeness magnitude may vary with time.

The statistical procedures proposed by $\mathrm{Stepp}^{23}$ are used to assess completeness time of the reported magnitudes. In this process the earthquakes in the catalog are grouped in different magnitude class. Each magnitude is modeled as a point process in time and means rate of occurrence of earthquakes in a magnitude range is established. To obtain an efficient estimate of the sample mean, it is assumed that the earthquake sequences can be modeled as a Poison Distribution. If $\mathrm{k}_{1}, \mathrm{k}_{2} \ldots \ldots \mathrm{k}_{\mathrm{n}}$ are the number of earthquakes per unit time interval then an unbiased estimate of the mean rate per unit time interval of this sample ${ }^{24}$ is-

$$
\lambda=\left(\frac{1}{n}\right) \sum_{i=1}^{n} k_{i}
$$

and its variance is-

$$
\sigma_{\lambda}^{2}=\frac{\lambda}{n}
$$

where $\mathrm{n}$ is the number of unit time interval. Considering the unit time interval to be one year duration, we get-

$$
\sigma_{\lambda}=(\lambda / T)^{\frac{1}{2}}
$$

as the standard deviation of the estimate of the mean, where $\mathrm{T}$ is the duration of the sample. If the earthquake data series were to be stationary $\lambda$ were to be constant which implies that $\sigma_{\lambda}$ would vary as $\frac{1}{\sqrt{T}}$. Following stepp

(1972) the standard deviation of the mean rate as a function of sample length are plotted along with nearly tangent lines with slope $\frac{1}{\sqrt{T}}$. The deviation of standard deviation of the estimate of the mean from the tangent

line indicates the length up to which a particular magnitude range may be taken to be completed.

\section{Result And Discussion:}

Figure (1) shows the frequency magnitude distribution (FMD) of earthquakes in the study area from 1901 - 2010. At the lower magnitude end at $\mathrm{M}=4 \mathrm{M}_{\mathrm{b}}$ the observation do not follow the Gutenberg Richter power law any longer and this is the threshold or completeness magnitude $\left(\mathrm{M}_{\mathrm{c}}\right)$ of the catalog. The green line represents the best fit to the observations in the area of complete recording. The slope of the green line is the $b$ value of the Gutenberg-Richter relationship. Magnitude smaller than $\mathrm{M}_{\mathrm{c}}$ departs from the best fit line because not all of these small earthquakes are reported. Moreover these events are harmless and of less interesting from the point of earthquake resistant designing. Hence the earthquakes of magnitude $<4 \mathrm{M}_{b}$ are excluded from further analysis.

The total 110 year sample is divided into 10 years sub-intervals in which $\lambda$ is stable in each magnitude class and it is assumed that this represents the interval of complete reporting for that magnitude class of earthquakes. The rates of occurrence of earthquakes of different magnitude in the study region as a function of time interval are listed in table (1) for magnitude 4 to $\geq 7 \mathrm{M}_{\mathrm{b}}$. The rate is given as $\mathrm{N} / \mathrm{T}$, where $\mathrm{N}$ is the cumulative number of earthquake in time interval $\mathrm{T}$ for sub- interval of 110 year sample. These data listed in table (2) are used to compute the standard deviation of the estimates of mean using equation (4). The standard deviations of the mean rate as a function of sample length are plotted along with nearly tangent lines with slope 
$\frac{1}{\sqrt{T}}$ as shown in figure (2). The deviation of standard deviation of the estimate of the mean from the tangent line

indicates the length up to which a particular magnitude range may be taken to be completed. It is observed from the graph that events with magnitude range $4-4.9 \mathrm{Mb}$ are completely reported only during the last 20 year (1990-2010) of the catalog while the earthquakes having magnitude range 5-5.9 $\mathrm{M}_{\mathrm{b}}$ are completely reported for about the last 50 years (1960-2010). The analysis also shows that the present catalog contains almost all the event of magnitude range 6-6.9 $\mathrm{M}_{\mathrm{b}}$ of last 90 years. Magnitude range $\geq 7 \mathrm{M}_{\mathrm{b}}$ are seems to be completely reported for the whole study period (i.e. 1901-2010).

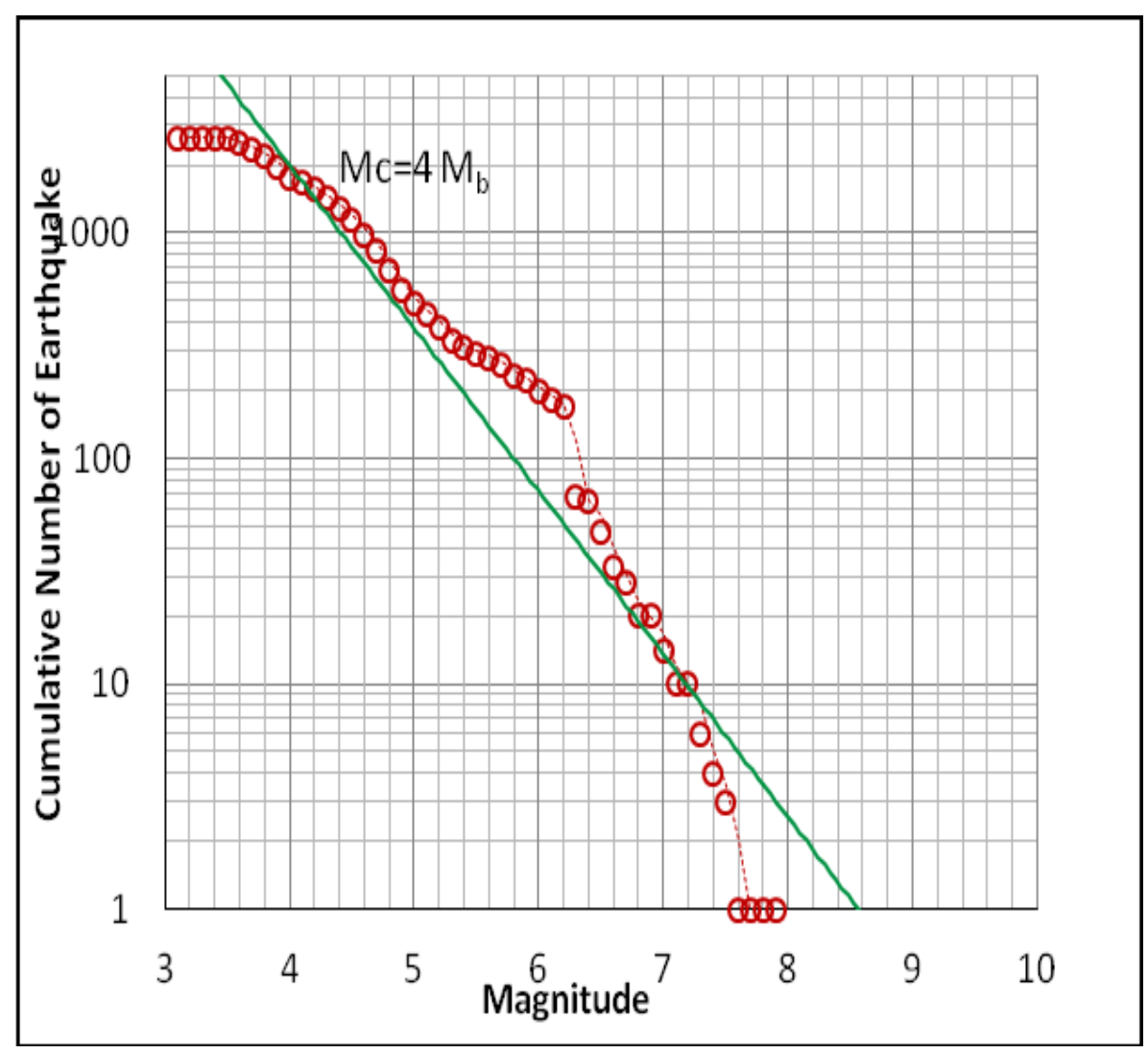

Fig (1): Cumulative number of earthquake versus magnitude with trend line. $M_{c}=4 M_{b}$.

Table (1): Rate of earthquake occurrence for different magnitude range and different time intervals based upon the past records.

\begin{tabular}{|c|c|c|c|c|c|c|c|c|c|}
\hline \multirow{3}{*}{ Decade } & \multirow{3}{*}{$\begin{array}{c}\mathrm{T} \text { in } \\
\text { years }\end{array}$} & \multicolumn{8}{|c|}{ Magnitude in $\mathrm{Mb}$} \\
\hline & & \multicolumn{2}{|c|}{$4-4.9$} & \multicolumn{2}{|c|}{$5-5.9$} & \multicolumn{2}{|c|}{$6-6.9$} & \multicolumn{2}{|c|}{$\geq 7$} \\
\hline & & $\mathrm{N}$ & $\lambda$ & $\mathrm{N}$ & $\lambda$ & $\mathrm{N}$ & $\lambda$ & $\mathrm{N}$ & $\lambda$ \\
\hline $2001-2010$ & 10 & 429 & 42.9 & 55 & 5.5 & 1 & 0.1 & 0 & \\
\hline 1991-2010 & 20 & 856 & 42.8 & 113 & 5.65 & 6 & 0.3 & 0 & \\
\hline $1981-2010$ & 30 & 1126 & 37.53 & 194 & 6.47 & 7 & 0.23 & 1 & 0.03 \\
\hline $1971-2010$ & 40 & 1256 & 31.4 & 241 & 6.02 & 10 & 0.25 & 1 & 0.03 \\
\hline $1961-2010$ & 50 & 1256 & 25.12 & 281 & 5.62 & 28 & 0.56 & 1 & 0.02 \\
\hline 1951-2010 & 60 & 1256 & 20.93 & 290 & 4.83 & 61 & 1.02 & 3 & 0.05 \\
\hline 1941-2010 & 70 & 1256 & 17.94 & 291 & 4.15 & 135 & 1.92 & 9 & 0.13 \\
\hline $1931-2010$ & 80 & 1256 & 15.7 & 291 & 3.64 & 161 & 2.01 & 11 & 0.14 \\
\hline 1921-2010 & 90 & 1256 & 13.96 & 291 & 3.23 & 183 & 2.03 & 11 & 0.12 \\
\hline 1911-2010 & 100 & 1256 & 12.56 & 292 & 2.92 & 184 & 1.84 & 13 & 0.13 \\
\hline 1901-2010 & 110 & 1256 & 11.42 & 292 & 2.65 & 185 & 1.68 & 14 & 0.13 \\
\hline
\end{tabular}


Table (2): Standard deviation $\left(\sigma_{\lambda}\right)$ of the estimates of mean recurrence rate per year $(\lambda)$.

\begin{tabular}{|c|c|c|c|c|c|c|c|c|}
\hline \multirow{4}{*}{ Time duration } & \multicolumn{8}{|c|}{ Magnitude in $\mathrm{Mb}$} \\
\hline & \multicolumn{2}{|c|}{$4-4.9$} & \multicolumn{2}{|c|}{$5-5.9$} & \multicolumn{2}{|c|}{$6-6.9$} & \multicolumn{2}{|c|}{$\geq 7.9$} \\
\hline & & $\sigma_{\lambda}$ & & $\sigma_{\lambda}$ & & $\sigma_{\lambda}$ & & $\sigma_{\lambda}$ \\
\hline & $\lambda$ & & $\lambda$ & & $\lambda$ & & $\lambda$ & \\
\hline 10 & 42.9 & 2.07 & 5.5 & 0.74 & 0.1 & 0.1 & & \\
\hline 20 & 42.8 & 1.46 & 5.65 & 0.53 & 0.3 & 0.12 & & \\
\hline 30 & 37.53 & 1.12 & 6.47 & 0.46 & 0.23 & 0.09 & 0.03 & 0.03 \\
\hline 40 & 31.4 & 0.89 & 6.02 & 0.39 & 0.25 & 0.08 & 0.03 & 0.03 \\
\hline 50 & 25.12 & 0.71 & 5.62 & 0.34 & 0.56 & 0.11 & 0.02 & 0.02 \\
\hline 60 & 20.93 & 0.59 & 4.83 & 0.28 & 1.02 & 0.13 & 0.05 & 0.03 \\
\hline 70 & 17.94 & 0.51 & 4.15 & 0.24 & 1.92 & 0.17 & 0.13 & 0.04 \\
\hline 80 & 15.7 & 0.44 & 3.64 & 0.21 & 2.01 & 0.16 & 0.14 & 0.04 \\
\hline 90 & 13.96 & 0.39 & 3.23 & 0.19 & 2.03 & 0.15 & 0.12 & 0.03 \\
\hline 100 & 12.56 & 0.35 & 2.92 & 0.17 & 1.84 & 0.14 & 0.13 & 0.03 \\
\hline 110 & 11.42 & 0.32 & 2.65 & 0.15 & 1.68 & 0.12 & 0.13 & 0.03 \\
\hline
\end{tabular}

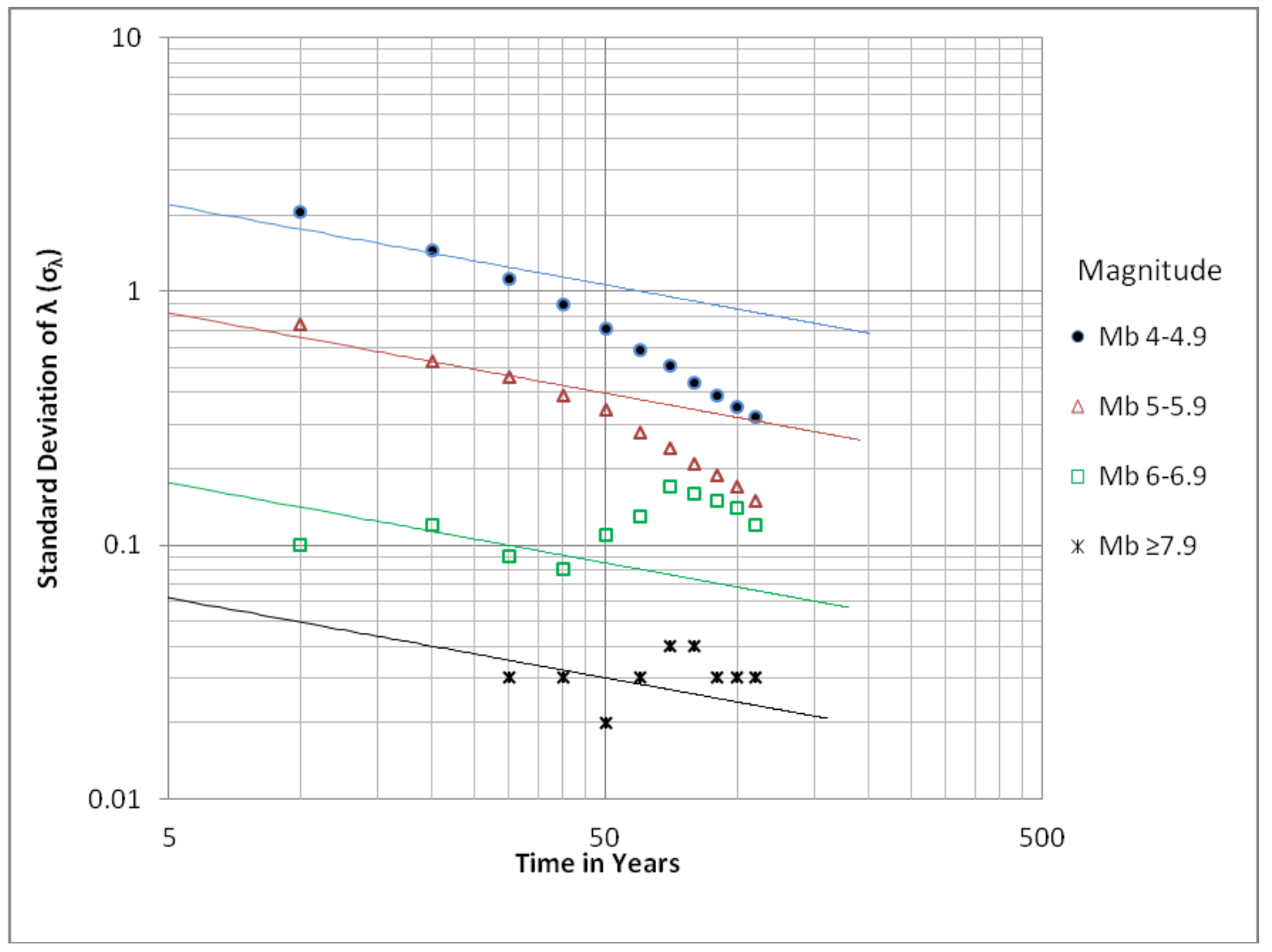

Figure (2): Completeness test of earthquake data of the study area. Variation of $\sigma_{\lambda}$ versus time interval and magnitude and lines with slope $\left(\frac{1}{\sqrt{T}}\right)$.

\section{Conclusion:}

There is underreporting of the lower magnitude earthquake in the earlier periods of the 110 years earthquake catalog compared to recent ones. The completeness analysis shows that the catalog is complete for whole period for larger magnitude $\geq 7 \mathrm{M}_{\mathrm{b}}$. Earthquakes having magnitude range 6-6.9 $\mathrm{M}_{\mathrm{b}}, 5-5.9 \mathrm{M}_{\mathrm{b}}$ and 4$4.9 \mathrm{M}_{\mathrm{b}}$ may be considered to be completely recorded since 1921, 1961 and 1991 respectively. An important feature of Stepp method is its ability to determine the time required for stable mean recurrence rate of 
magnitudes. This makes it possible to create an artificially homogeneous and complete data sample, thus allowing for statistical studies to be performed. In the present study the stable mean recurrence rate of the earthquakes having magnitude classes 4-4.9 $\mathrm{M}_{\mathrm{b}}, 5-5.9 \mathrm{M}_{\mathrm{b}}, 6-6.9 \mathrm{M}_{\mathrm{b}}$ and $\geq 7 \mathrm{M}_{\mathrm{b}}$ is found to be 10, 30, 40 and 90 years respectively.

\section{Acknowledgement:}

The author is thankful to Gauhati University Library Authority for giving the permission to use the Reference Section as well as the Digital Library, Principal of Barbhag College, Kalag for allowing and inspiring to carry out the study and the Department of Statistics of B.H. College, Howly, Assam for helping in statistical analysis of the data of the paper.

\section{Reference:}

[1]. Chandra, U. (1992): Seismotectonics of Himalaya, Current Science, 62 (1-2), 40-71.

[2]. Guha, S.K. and Basu (1993): Catalogue of earthquakes ( $>3.0)$ in Peninsular India, AERB Technical Document No. TD/CSE -1, pp. $1-70$.

[3]. Baruah, Saurav and Hazorika. D., (2008): A GIS based tectonic map of Northeastern India, Current Science, Vol. 95, No. 25 July 2008 .

[4]. Kuge, K. (1992): Systematic difference in the ISC body wave magnitude- seismic moment relationship between intermediate and deep earthquakes. Bull. Seismol. Soc. Am. Vol. 82, pp. 819-835.

[5]. Smith, G.P. and Ekstrom, G. (1995): Using travel time and wave form data to study the earthquake source. In Proc. of Fall AGU meeting. Eos. Trends. AGU, Vol. 76 (46). F 389 (Abstract).

[6]. Smith, G.P. and Ekstrom, G. (1997): Interpretation of earthquake epicenter and CMT centroid locations, in terms of rupture length and direction. Phys. Earth Planet. Inter. Vol. 102, pp. 123-132.

[7]. Harte, D. and Vere-Jones, D. (1999): Differences in coverage between the PDE and New Zealand local earthquake catalogs. New Zealand Jr. Geol. Geophys. Vol. 42, pp. 237-253

[8]. Rohm, A. H., Trampert, J., Paulssan, H. and Sneider, R.K., (1 Patton, H.J., (2001): Regional magnitude scaling, transportability and $\mathrm{M}_{\mathrm{s}}: \mathrm{M}_{\mathrm{b}}$ discrimination at small magnitudes. Pure Appl. Geophys. Vol. 158, pp. 1951-2015.

[9]. Storchak, D.A., Bird, A.L. and Adams, R.D. (2000): Discrepancies in earthquake location between ISC and other agencies. Jr. Seism. Vol 4, pp. 321-331.

[10]. Patton, H.J., (2001): Regional magnitude scaling, transportability and $\mathrm{M}_{\mathrm{a}} \mathrm{M}_{\mathrm{b}}$ discrimination at small magnitudes. Pure Appl. Geophys. Vol. 158, pp. 1951-2015.

[11]. Stepp, J.C. (1973): Analysis of completeness of the earthquake sample in the Puget Sound area. In: Harding ST (ed) Seismic Zoning. NOAA Tech. Report ERL 267-ESL30, Boulder Colorado.

[12]. Kagan, Y.Y., (2003): Accuracy of modern global earthquake catalogs. Phys. Earth and Planetary Interiors, Vol. 135, pp. 173-209.

[13]. Redelek, P.A. and Sacks, I. S., (1989): Testing the completeness of earthquakecatalogs and the hypothesis of self-similarity, Nature. Vol. 337, pp.251-253

[14]. Taylor, D.W. A., Snoke, I. A., Sacks,I. S. and Takanami, T., (1990): Nonlinear frequency-magnitude relationship for the Hokkaido corner, Japan, Bull. Seism. Soc. Am. Vol.80, pp.340-353.

[15]. Wiemer, S., and M. Wyss (2000): Minimum Magnitude of complete reporting earthquake catalogs; examples from Alaska, the Western United States and Japan. Bull. Seism. Soc. Am. Vol. 90, pp.859-869.

[16]. Richter, C.F. (1958), Elementary Seismology, W.H. Freeman \& Co. Inc., San Francisco, USA.

[17]. Ischimoto, M. and Iida, K., (1939): Observations Sur les Seisms enregistre par le microismograph construite dernierment microseismograph construite dernierment (I), Bull. Earthq. Res. Inst., 17 (1939), 443-478, (in Japanese with French summary).

[18]. Gutenberg, B. and Richter, C.F. (1944): Frequency of earthquake in California. Bull.Seism.Soci. Am., V.34. pp. 7507-7514.

[19]. Riznichenko,J.V.,(1959):On quantitative determination and maping of Seismic activity. Am. Geophys. Vol.12. pp. 227-237.

[20]. Mignan, A., J. Woessner (2012), Estimating the magnitude of completeness for earthquake catalog, Community Online Resource for Statistical Seismicity Analysis, doi: 10.5078/corssa-00180805. Available at http://www. Corssa.org

[21]. Naylor, M., K. Orfanogiannaki, and D. Harte (2010), Exploratory data analysis: magnitude, space, and time, Community Online Resource for Statistical Seismicity Analysis, Available at http://www. corssa.Org.doi:10.5078/corssa-92330203. 3, 5, 7, 37

[22]. Wesnousky, S. G. (1994): The Gutenberg-Richter or Characteristic Earthquake Distribution, Which Is It, Bull. Seismol. Soc. Am. Vol.,84., $1940\{1958.5,21$

[23]. Stepp, J.C. (1972), Analysis of completeness of the earthquake sample in the Puget sound area and its effect on statistical estimates of earthquake hazard. In International Conference on Microzonation, II, 897-909

[24]. Hamilton, W.C., (1964): Statistics in Physical Science., The Ronald Press Co., N. Y., pp.230. 